\title{
Non-invasive imaging in the diagnosis of acute viral myocarditis
}

\author{
Michael Jeserich · Stavros Konstantinides · \\ Gabor Pavlik · Christoph Bode · Annette Geibel
}

Received: 15 December 2008/Accepted: 13 August 2009/Published online: 11 September 2009

(C) The Author(s) 2009. This article is published with open access at Springerlink.com

\begin{abstract}
Autopsy series of consecutive cases have demonstrated an incidence of myocarditis at approximately $1-10 \%$; on the contrary, myocarditis is seriously underdiagnosed clinically. In a traditional view, the gold standard has been myocardial biopsy. However, it is generally specific but invasive and less sensitive, mostly because of the focal nature of the disease. Thus, non-invasive approaches to detect myocarditis are necessary. The traditional diagnostic tools are electrocardiography, laboratory values, especially troponin $\mathrm{T}$ or I, creatine kinase and echocardiography. For a long period, nuclear technique with indium-111 antimyosin antibody has been used as a diagnostic approach. In the last years, the use of this technique has declined because of radiation exposure and 48-h delay in obtaining imaging after injection to prevent blood pool effect. Thus, a non-invasive diagnostic approach without radiation and online image availability has been awaited. Cardiac magnetic resonance imaging has
\end{abstract}

M. Jeserich · C. Bode · A. Geibel

Department of Cardiology and Angiology, Albert Ludwig

University of Freiburg, Freiburg, Germany

S. Konstantinides

Department of Cardiology and Pulmonary Medicine,

Georg August University of Goettingen,

Robert Koch Strasse 40, Göttingen 37085, Germany

G. Pavlik

Department of Health Sciences and Sports Medicine, Faculty of Physical Education and Sports Sciences,

Semmelweis University, Budapest, Hungary

M. Jeserich $(\square)$

Koenigstr. 39, 90402 Nuremberg, Germany

e-mail: info@Praxis-Jeserich.de; MJeserich@aol.com these promising characteristics. With this technique, it is possible to analyse inflammation, oedema and necrosis in addition to functional parameters such as left ventricular function, regional wall motion and dimensions. Thus, cardiovascular magnetic resonance imaging has emerged as the most important imaging tool in the diagnostic procedure and the review focus on this field. But there are also advances in echocardiography and computer tomography, which are described in detail.

Keywords Myocarditis - Magnetic resonance . Non-invasive imaging · Echocardiography .

Nuclear medicine $\cdot$ Computer tomography

\section{Introduction}

Acute myocarditis may cause substantial myocardial damage and can lead to arrhythmias, sudden cardiac death in the acute phase and to dilated cardiomyopathy in the acute and chronic phase [1,2]. Therefore, early diagnosis is of particular clinical importance. Myocarditis can be diagnosed with certainty only by endomyocardial biopsy, which must be examined by histological, immunohistological and molecular techniques to obtain maximal sensitivity. Due to the often focal localisation of the disease, sampling error may occur. Furthermore, myocardial biopsy is in practise used only rarely, despite a low complication rate [3]. Thus, the diagnosis of myocarditis is often based merely on suspicion.

Viral myocarditis is found after respiratory or gastrointestinal infection with a wide range of viruses. In the seventies, the RNA virus coxsackie B was the most common cause [4]. Other viruses included adeno-, varicella zoster, cytomegalie and Epstein-Barr. In the presence, 
parvovirus B19 and human herpesvirus 6 are increasingly found in endomyocardial biopsies [5-10].

Clinical symptoms, the course and diagnostic approach in patients with suspected myocarditis

Clinical symptoms, such as weakness, palpitations, fatigue, are often minor and are mistaken in many cases as part of the previous infection or delayed convalescence. However, sudden cardiac death in persons active in sports-especially with people younger than 35 years-is often due to non-detected acute myocarditis [11].

In virus myocarditis, the acute phase of the disease is triggered by the entry and proliferation in the myocardium of the causative virus. Various cytokines are activated. Circulating levels of plasma tumour necrosis factor and various interleukins are elevated [12, 13]. Infiltrating $\mathrm{T}$ lymphocytes and macrophages can be detected in the acute and chronic phase by biopsy [14]. The acute phase of myocarditis is characterised by myocyte necrosis and cellular infiltrates in the myocard whereas in case of chronic myocarditis no myocyte necrosis but cellular infiltrates could be detected. Not only in the chronic phase but also in the acute phase, deterioration of the left function and dilated cardiomyopathy may occur [13]. Kühl et al. [5] demonstrated that patients with persisting viral genomes detected by myocardial biopsy showed a progressive impairment of left ventricular function, whereas spontaneous viral elimination was associated with a significant improvement in left ventricular function. In contrast to this finding, Kindermann et al. [15] found in 181 consecutive patients who underwent endomyocardial biopsy as part of an evaluation for clinically suspected myocarditis that for the primary end point of cardiac death or heart transplantation, NYHA functional classes III and IV, high values of the left ventricular end-diastolic diameter index and pressure, a low ejection fraction, and immunohistological detection of inflammation were shown to be significant predictors of poor outcome in the univariate analysis, whereas the Dallas criteria and viral genome detection were not significantly related to outcome. The difference might be due to patient population, sample collection and the fact that in the study by Kühl et al. [5] the patients were reanalysed by endomyocardial biopsy at a median period of 6.8 months (range 5.4-11.9) which was not performed in the study by Kindermann et al. [15]. Thus, it is not known in which patients a clearance of the viral genomes occurred.

Electrocardiography and laboratory values

ST segment and T-wave abnormalities are the typical electrocardiographic patterns, but they are usually transient. Other electrocardiographic abnormalities include atrial and ventricular arrhythmias, AV and intraventricular conduction defects and variant early repolarisation [16, 17]. But there exist several patients without electrocardiographic abnormalities. Eckart et al. [17] found in patients with vaccinia-associated myopericarditis despite markedly elevated cardiac enzymes in $25 \%$ a normal electrocardiogram. Routine laboratory investigations include troponin $\mathrm{T}$ or I, myoglobine, and creatine kinase levels. Raised troponin levels reflect myocardial necrosis [18]. There are a large number of causes of an elevated troponin, which include acute coronary syndrome, myocarditis, cardiomyopathy, cardiac contusion, aortic dissection, congestive heart failure, amyloidosis and non-cardiac causes including pulmonary embolism, sepsis and renal failure [19-21]. In patients with acute chest pain, elevated troponin and unobstructed coronary arteries, myocarditis is a common cause $[14,22]$. But there are several patients with normal electrocardiogram and negative troponin or creatine kinase levels but suspected myocarditis especially after or during a viral infection of the respiratory or gastrointestinal tract. Carniel et al. [23] found in a consecutive series of autopsies of fatal myocarditis an elevated creatine kinase only in $18 \%$ of the patients. In addition, even in patients with ECG changes, these are non-specific for myocarditis [3].

\section{Echocardiography}

Traditional echocardiographic findings are left ventricular regional or global dysfunction, and left ventricular dilatation. Pinamonti et al. [24] found in 41 patients with histologically proven myocarditis left ventricular dysfunction in $69 \%$, right ventricular dysfunction in $23 \%$, asynergic ventricular areas in $64 \%$, left ventricular "hypertrophy" sometimes reversible in $20 \%$, ventricular thrombi in $15 \%$ and "restrictive" ventricular filling in $7 \%$ of his patients.

Right ventricular function is an independent predictor of outcome. Mendes et al. [25] assessed the predictive value of right ventricular systolic function in patients with active myocarditis in 23 patients with biopsy-confirmed myocarditis. Initial left ventricular ejection fraction was significantly lower in patients with depressed right ventricular function $(27.5 \pm 4.9 \%)$ compared with that in patients with normal right ventricular function $(47.5 \pm 6.3 \%)$ $(P=0.01)$. The likelihood of an adverse outcome, defined as death or need for cardiac transplantation, was greater in patients with abnormal right ventricular function.

The presence of myocardial interstitial oedema in acute myocarditis leads to thickening of the ventricular wall, which can be detected by echocardiography [26]. Felker et al. [27] distinguished fulminant myocarditis with rapid onset of illness with severe haemodynamic compromise 
from acute myocarditis by echocardiographic criteria of septal thickness and left ventricular dimensions. Patients with fulminant myocarditis had near normal left ventricular dimensions $(5.3 \pm 0.9 \mathrm{~cm})$ but increased septal thickness $(1.2 \pm 0.2 \mathrm{~cm})$ at presentation, while those with acute myocarditis had increased diastolic dimensions $(6.1 \pm$ $0.8 \mathrm{~cm}, P<0.01 \mathrm{vs}$. fulminant) but normal septal thickness $(1.0 \pm 0.1 \mathrm{~cm}, P=0.01$ vs. fulminant). Fulminant myocarditis has a better long-term prognosis than acute myocarditis as shown in the clinical study of McCarthy et al. [28].

There are few case reports of detecting myocarditis by novel echocardiographic modalities such as tissue Doppler, strain and strain rates or three-dimensional echocardiography [29-31]. Di Bella et al. [29] report a case where strain Doppler echocardiography was able to identify longitudinal segmental myocardial dysfunction derived from oedema in the acute phase of myocarditis. Smedema [30] demonstrates in a case report the value of tissue Doppler echocardiography and contrast-enhanced cardiac magnetic resonance imaging (CMRI) in the diagnosis and management of patients with myocarditis. Tissue Doppler imaging demonstrated abnormalities suggestive of myocardial scar, which was confirmed by magnetic resonance. Thuny et al. [31] revealed by real-time two- and three-dimensional echocardiography in a 43-year-old man with myocarditis a dilated and hypokinetic left ventricle and massive biventricular thrombosis that was better assessed by real-time, three-dimensional transthoracic echocardiogram.

Nuclear medicine techniques

\section{Gallium-67}

In the early $80 \mathrm{~s}$, scintigraphy has been used in evaluating myocarditis. O'Connell et al. [32] evaluated the applicability of gallium-67 myocardial imaging as an adjunct to endomyocardial biopsy in the diagnosis of myocarditis in 68 patients with dilated cardiomyopathy. Histologic myocarditis was identified in only $8 \%$ of biopsy specimens. Five of six biopsy samples (87\%) with myocarditis showed dense gallium-67 uptake, whereas only 9 of 65 negative biopsy samples $(14 \%)$ were paired with equivocally positive gallium-67 scans $(P<0.001)$. The introduction of single photon emission computed tomography (SPECT) improved the differentiation between pericardial and myocardial localisation which was difficult with planar images alone $[33,34]$. The use of gallium imaging has diminished over time mainly because of a lack of specificity [35].

\section{Indium-111}

In 1976, Khaw et al. [36] reported a specific localisation of a purified antibody against cardiac myosin. Intravenously administered radioiodine-labelled antimyosin was selectively localised in infarcted myocardium of seven dogs $24 \mathrm{~h}$ after coronary occlusion. Yasuda et al. [37] were the first who reported the use of an indium 111-monoclonal antimyosin antibody imaging in the diagnosis of acute myocarditis. Because indium 111-monoclonal antimyosin antibody imaging can be used to detect myocardial necrosis, they performed this procedure on 28 patients clinically suspected of having myocarditis, and compared the results with those of right ventricular biopsy performed within $48 \mathrm{~h}$ of the scan. Antimyosin scans were positive in 17 patients and negative in 11 . Biopsy was positive in nine patients and negative in six. The remaining showed nonspecific changes. All patients with biopsy-proven myocarditis had positive antimyosin scans. In addition, eight patients with no evidence of myocarditis on biopsy had positive antimyosin scans. On the basis of a right ventricular biopsy standard, the sensitivity of this method was $100 \%$, the specificity $58 \%$. Kühl et al. [38] compared the results of antimyosin scintigraphy in patients with clinically suspected myocarditis with histologic and immunohistologic findings in the endomyocardial biopsy. They found that, with immunohistologic analysis as the reference method, antimyosin scintigraphy had a high specificity but a lower sensitivity for the detection of myocarditis. During the following years, the results were confirmed by others [39-42]. During more than 20 years, antimyosin scans remained an important cornerstone in the diagnosis of myocarditis [43].

\section{Other tracers}

Myocardial perfusion imaging with technetium-99 mlabelled methoxyisobutyl isonitrile SPECT (99mTc-MIBI SPECT) has proven to be an important clinical procedure in assessing the severity of myocardial ischaemia [44]. The uptake and clearance of $99 \mathrm{mTc}-\mathrm{MIBI}$ by the myocardium is affected by cell viability and membrane integrity. Consequently, infectious diseases, such as myocarditis, may also affect myocardial perfusion by inducing local inflammation and necrosis. Sun et al. [44] compared 99mTc-MIBI SPECT with other heart monitoring methods in order to assess its value in the diagnosis of children with Coxsackie viral myocarditis. The results of their study suggest that the presence of myocardial uptake of $99 \mathrm{mTc}$ MIBI may be a marker of myocardial inflammation and necrosis. Thallium-201 myocardial perfusion defects at rest, suggestive of fibrosis evoked by myocarditis, were examined in orienteers and athletes [45], but no differences were found. These and other tracers have not often been used in clinical practise.

In conclusion, indium-111 antimyosin antibody imaging has been intensively used during more than two decades for 
diagnosis of myocarditis. Limitation of this technique includes its current limited availability in the US [46] radiation exposure, which is especially of concern in younger patients and 48-h delay in obtaining imaging after injection to prevent blood pool effects. Therefore, the application has diminished over the last years

\section{Cardiac magnetic resonance imaging}

During the passed decade, CMRI has emerged as an important procedure in the investigation of cardiovascular disease. With this technique, it is possible to analyse functional parameters such as left ventricular function, regional wall motion, dimensions and flow properties. In addition, it can characterise tissue to a greater degree than other imaging modalities and detect focal or global inflammation [6, 47].

T1-weighted images before and after gadolinium enhancement

Gadolinium diethylenetriamine pentaacetic acid (Gd-DTPA) is an approved extracellular T1-enhancing contrast agent [48] which enhances membrane permeability and capillary blood flow resulting in an increase in volume of distribution. Tissue hyperemia is an integral component of the acute inflammatory reaction of the myocardium. Diffuse myocyte injury can also increase the volume of distribution and subsequently the extraction fraction of extracellular compounds such as Gd-DTPA, resulting in abnormal myocardial enhancement [47, 49].

The group of Friedrich and Schulze-Menger et al. [47, 49] examined $\mathrm{T} 1$-weighted images, especially contrast media-enhanced, in comparison to healthy volunteers in patients with suspected myocarditis (acute phase). They found an increased global relative signal enhancement of the left ventricular myocardium compared to skeletal muscle in patients compared to volunteers. Roditi et al. [50] assessed a combination of different techniques including $\mathrm{T} 1$ spin echo before and after gadolinium enhancement in 12 patients with suspected acute myocarditis. Ten of 12 patients in the myocarditis group showed focal myocardial enhancement with associated regional wall motion abnormalities. Laissy et al. [51] prospectively compared the value of different CMRI modalities in patients with acute myocarditis. Subtraction Gd-DTPAenhanced T1-weighted CMRI accurately identified myocardial involvement. Gutberlet et al. [52] retrospectively compared the diagnostic accuracy of three CMRI approaches for the detection of histologic and immunohistologic criteria proved myocardial inflammation in patients clinically suspected of having chronic myocarditis. The sensitivity, specificity and diagnostic accuracy of the
T1-weighted imaging after contrast agent administration compared with the immunohistologic detection of inflammation were 62,86 and $72 \%$.

The relationship of CMRI findings to long-term outcome was studied in another study [53] by serial CMRI studies in 16 patients with acute myocarditis who were followed for 2-3 years. Myocardial contrast enhancement was monitored using contrast-enhanced T1-weighted fast spin echo images. Contrast enhancement 4 weeks after onset of symptoms was predictive for the functional and clinical long-term outcome.

There are some methodical concerns regarding T1 contrast-enhanced images: first, it is difficult to establish stable conditions after the application of Gd-DTPA. There is a continuous change of the zero run through after the application of the contrast media. Thus, it is a crucial point, at which time the images are performed. Secondly, the T1weighted images after Gd-DTPA are related to skeletal muscle. Thus, the relative enhancement depends on the assumption that the skeletal muscles exhibit a "normal" pattern of gadolinium enhancement. This assumption is wrong if the inflammatory process involves skeletal muscles as well [49]. Thirdly, T1 contrast-enhanced images in the diagnosis of myocarditis are only published by few investigators. Therefore, before a routine use of this image approach is used in daily practise, more studies from different centres should be performed. A native T1-weighted CMR sequence is, of course, of clinical use in the differentiation of pericardial effusion which may accompany myocarditis.

\section{T2-weighted images}

The tissue $\mathrm{T} 2$ relaxation time is an indicator of tissue water content, which is increased in inflammation or necrosis, i.e. during early myocardial infarction or myocarditis $[49,54]$. Gagliardi et al. [55, 56] published two case series on the use of CMR for non-invasive diagnosis of acute myocarditis. Compared with biopsy, T2-weighted spin echo CMRI sequences were found to have a high sensitivity and specificity. There are some case reports on patients with acute myocarditis using T2-weighted images to visualise tissue oedema [40, 57]. However, Friedrich et al. [47] found no significant myocardial signal increase in conventional T2weighted images in 44 patients. These images are susceptible to motion, and in native T2-weighted images the image quality of the myocardium is poor. In addition, the protocols were different and he used an $1.0 \mathrm{~T}$ hardware. New hardand software developments, especially a triple inversion press hold sequence with short acquisition time (STIR), have led to a much better image quality.

In the study by Abdel-Aty et al. [49], they used a STIR sequence as well. The increase in $\mathrm{T} 2$ signal intensity 
demonstrated a good accuracy in distinguishing patients with suspected myocarditis $(n=25)$ from control subjects $(n=24)$. We used in a series of 44 consecutive patients with suspected myocarditis after respiratory tract infection a STIR sequence as well. We found a significant difference between patients and controls in global myocardial signal intensity and in the ratio of global myocardial signal intensity/muscle signal intensity. The sensitivity was $77.8 \%$, the specificity $90.5 \%$, the positive predictive value $93.3 \%$, and the negative predictive value $70.4 \%$, and the diagnostic accuracy $82.5 \%$. In addition, the signal intensity of the septum, anterior and lateral wall was highly significant from controls [58] (Figs. 1, 2). Assomull et al. [22] and Gutberlet et al. [52] used novel T2-weighted sequences as well with good results in detecting myocarditis.

In conclusion, in patients clinically suspected of having myocarditis, a STIR sequence seems to have a good sensitivity, specificity and diagnostic accuracy in detecting tissue oedema, a substantial feature of the inflammatory reaction in the myocardium.

\section{Late enhancement technique}

Cardiac magnetic resonance imaging techniques have been applied to identify viable myocardium and distinguish it

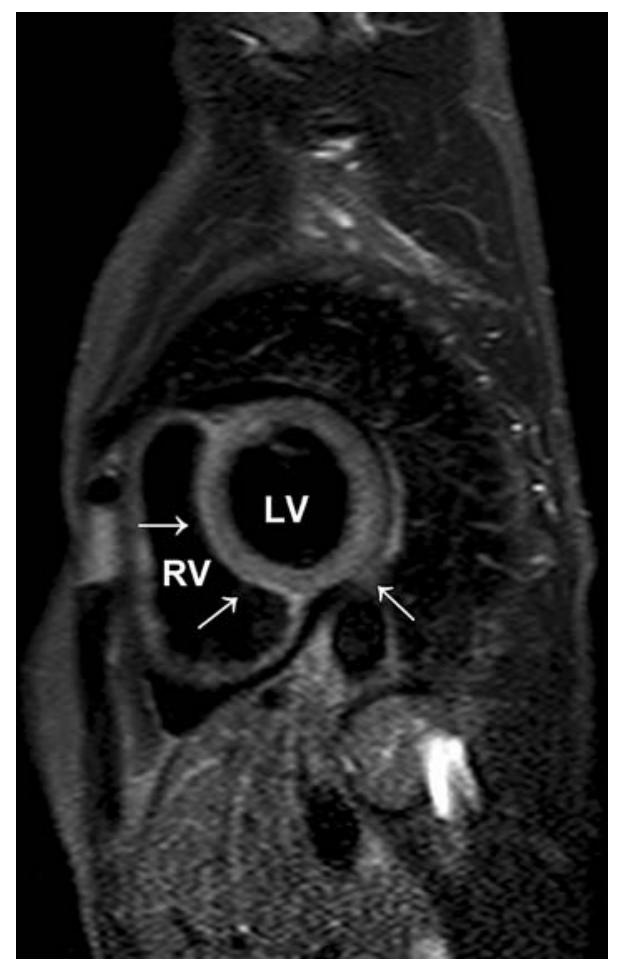

Fig. 1 Cardiovascular magnetic resonance image. Short-axis image of a 54-year-old female patient with acute myocarditis. T2-weighted image showing oedema of the septum, inferior and lateral wall (arrow). The patient had biopsy-proven myocarditis of isolated parvovirus B19 infection. $L V$ Left ventricle. $R V$ right ventricle from myocardial necrosis [59] (Fig. 3). Normal myocardium does not enhance because extracellular magnetic resonance contrast agents, such as Gd-DTPA, are excluded from the myocyte intracellular space by intact sarcolemmal membranes and also, little interstitial space is available between densely packed myocytes [60]. This technique has been shown to be effective, in both animals and humans, in identifying the presence, location and extent of acute and chronic myocardial infarction [59, 61]. The cellular mechanisms responsible for contrast enhancement have not been fully elucidated. The hypothesis is that in acutely infarcted regions the myocyte membranes are ruptured allowing the cardiovascular magnetic resonance contrast agent to passively diffuse into the intracellular space, resulting in increased tissue-level contrast agent concentration and therefore hyperenhancement [60].

The same mechanism may explain contrast enhancement in the setting of inflammatory heart disease. Images acquired late (10-20 min) after application of paramagnetic contrast agents provide a sensitive tool for detection of myocardial fibrosis, which is distinguished by bright late enhancement regions where the contrast lingers in the extracellular spaces of scarred myocardium [62]. The major difference to infarcted regions is that areas of tissue damage within a myocarditic focus are usually smaller than in infarcts. Islands of necrotic cells are dispersed in a "cougar-like pattern" throughout the focus [52, 63].

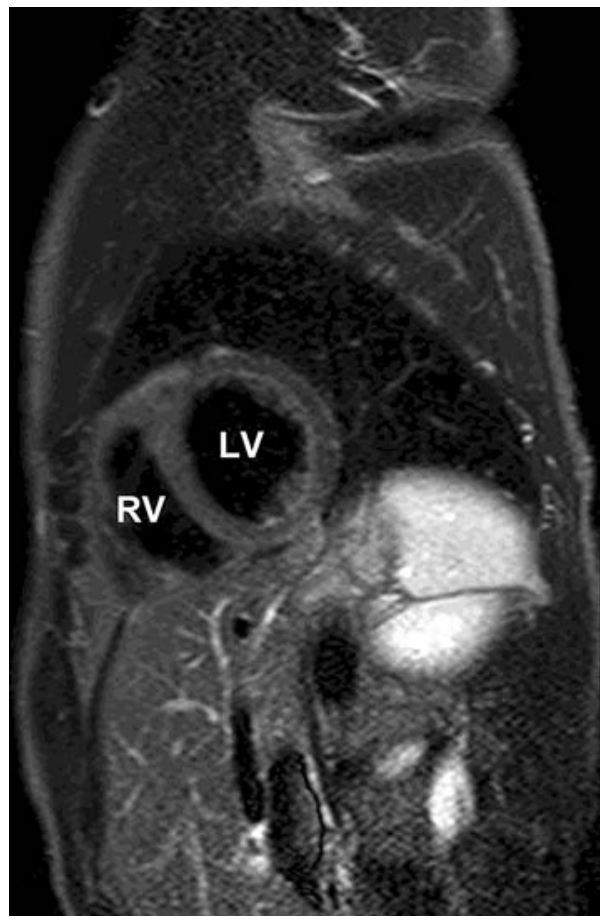

Fig. 2 Short-axis T2-weighted image of a control. There is a homogeneous signal of the myocardium. $L V$ Left ventricle. $R V$ right ventricle 


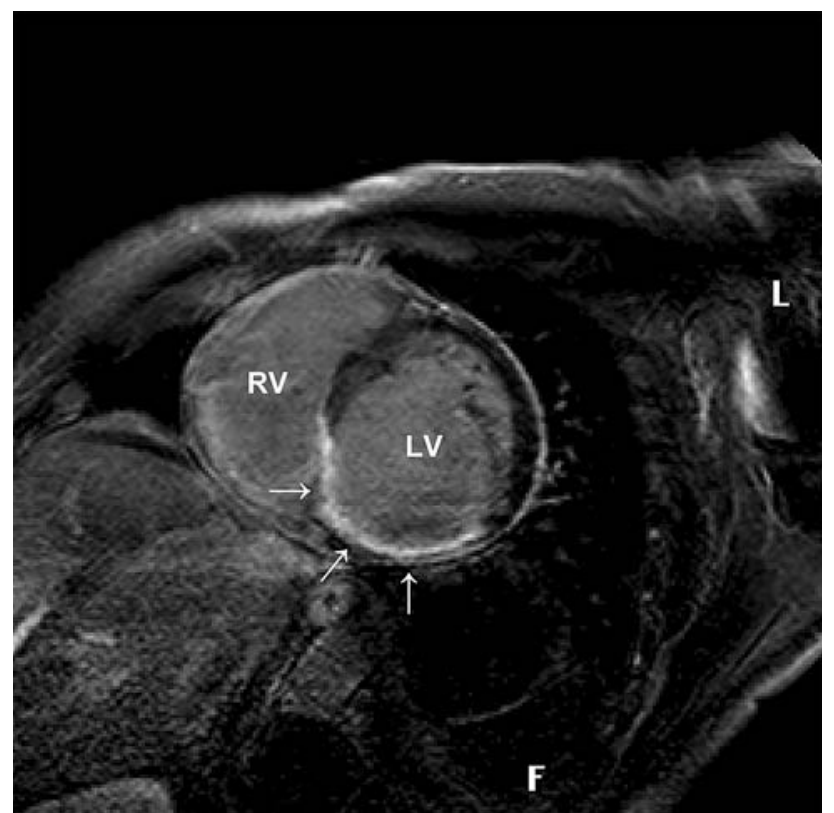

Fig. 3 Delayed enhancement imaging of a 50-year-old male patient with a chronic myocardial infarction. Short-axis view. There is a transmural scar of the inferoseptal wall (arrow). $L V$ Left ventricle. $R V$ right ventricle

In addition, hyper-enhanced myocardial regions can be visualised in patients with hypertrophic or dilatative cardiomyopathy [64]. CMRI has been examined in other cardiac diseases as well [65-69]. There are several case reports of the usefulness of delayed contrast-enhanced magnetic resonance imaging for the detection of myocarditis [70-72]. In controlled studies with patients suspected to have myocarditis, delayed contrast-enhanced cardiac magnetic resonance has been investigated as well [22, 49, 51, 73-75]. A typical subepicardial/midmyocardial late contrast enhancement is highly predictable of myocarditis in suspected patients [48, 75, 76] (Figs. 4, 5).

Cardiac magnetic resonance imaging studies are mainly performed in the acute phase of myocarditis. Mahrholdt et al. [6] found a pathological late gadolinium enhancement in 83 of 87 patients with confirmed acute myocarditis. Patients without histopathological evidence of myocarditis did not have late gadolinium enhancement except for one patient diagnosed with cardiac amyloidosis. In the setting of parvovirus B19 myocarditis, late gadolinium enhancement was located predominantly in the lateral wall of the left ventricle, typically originating from the epicardial quartile $(n=49)$. This was completely different from patients with human herpesvirus 6 myocarditis $(n=16)$, in whom pathological delayed enhancement was most frequently found in the anteroseptal region, often located intramurally, without any contact with the subepicardial region. In the setting of combined parvovirus B19/human herpesvirus 6 myocarditis, the pattern was similar, not only

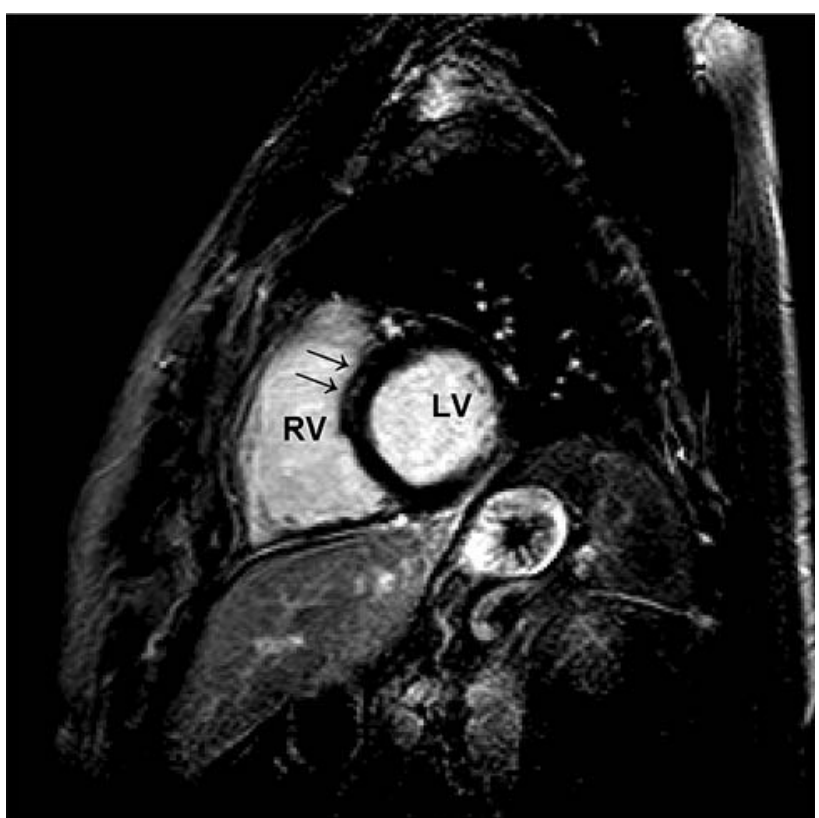

Fig. 4 Delayed enhancement imaging of a 42-year-old male patient with viral myocarditis, exertional dyspnoe after a gastrointestinal infect. Short-axis view demonstrating a small enhanced mid-wall signal intensity of the left ventricular septum (arrow). LV Left ventricle. $R V$ right ventricle

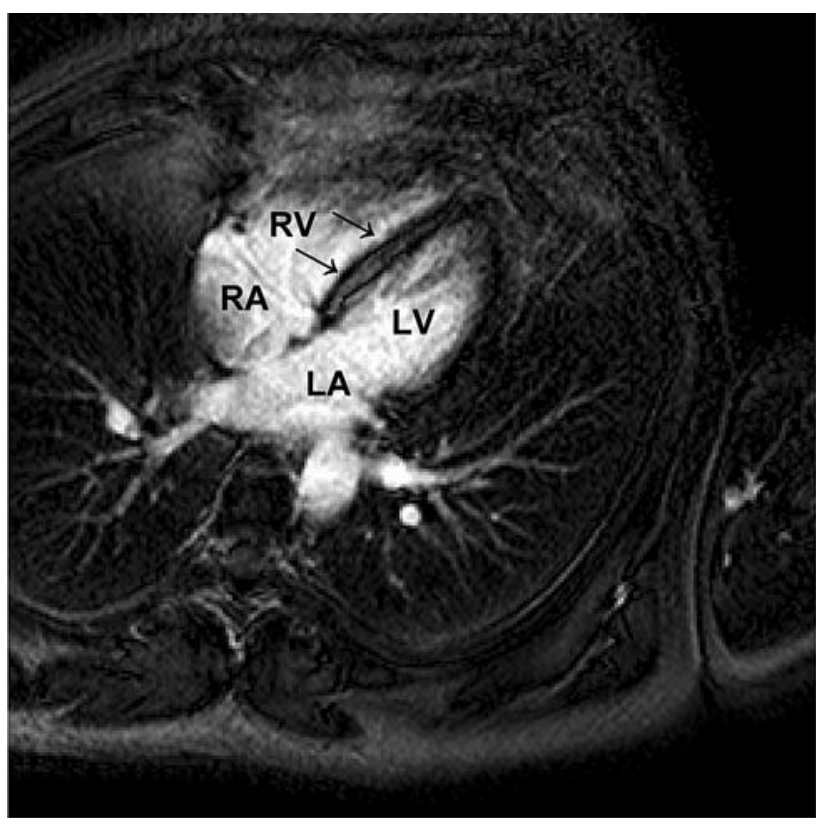

Fig. 5 Delayed enhancement imaging of a 61-year-old male patient with viral myocarditis, fatigue and frequent ventricular premature beats after a respiratory infect. Four-chamber view demonstrating enhanced mid-wall signal intensity of the left ventricular septal myocardium (arrow). $L V$ Left ventricle. $R V$ right ventricle. $L A$ Left atrium. $R A$ right atrium

affecting the anteroseptal myocardium but also forming a mid-wall area of damage in the entire septum. Myocardial biopsies targeted to areas with late gadolinium 
enhancement show histological evidence of myocarditis in patients [6].

In a study, Gutberlet et al. [52] analysed 83 patients with chronic myocarditis. They found a lower sensitivity and accuracy of T1- and T2-weighted images. Their specificity was acceptable with $80 \%$. The authors found no association with polymerase chain reaction proof of viral genomes, but a correlation with T1- and T2-weighted images and intramyocardial inflammation. Thus, CMRI findings have to be interpreted different if it is used in the acute phase or in the chronic phase of myocarditis. In the acute phase, an enhanced signal in T2-weighted images and in T1 contrastenhanced images is a typical finding whereas this is not the case in chronic myocarditis. At presence, a major limitation of CMRI is that it cannot detect viral persistence.

In conclusion, in patients with suspected myocarditis, cardiovascular magnetic resonance tomography including a high sensitive, specific and robust fast spin echo triple inversion recovery sequence (STIR) is helpful in decisionmaking. The CMR study should include a late enhancement sequence. T1-weighted native image is recommended in patients with additional pericardial effusion. T1-weighted spin echo after gadolinium injection might be added.

Accuracy of cardiovascular magnetic resonance in relation to biopsy-confirmed cases

The traditional diagnosis of viral myocarditis relies upon the histological (Dallas) criteria. Evaluation of endomyocardial biopsy specimens by use of these criteria may give negative results despite clear clinical evidence for acute myocarditis $[3,49]$. There is a sensitivity of only $25-40 \%$ reported [3, 77, 78]. To date, techniques, in particular immunohistochemistry and viral polymerase chain reaction, and magnetic resonance guided endomyocardial biopsies have lead to substantial improvement of diagnostic accuracy of endomyocardial biopsy [6, 52, 79]. Thus, endomyocardial biopsy remains the diagnostic gold standard in myocarditis and in viral myocarditis in particular. Table 1 depicts cardiovascular magnetic resonance in relation to biopsy-confirmed cases. The majority of the studies involved only small number of cases. In addition, there are different methods for the evaluation of myocardial oedema used. In older studies, a T1 spin echo or T2 spin echo sequence was used $[49,50,55]$. In some studies, no late enhancement technique was performed [49, 50, 55]. Recent studies compared different cardiovascular magnetic approaches with biopsy results [52, 73], and magnetic resonance guided endomyocardial biopsies [6]. Especially, the latter study has shown a very good accuracy between the late enhancement technique and biopsy-proven myocarditis of $95 \%$. In the study of Gutberlet et al. [52], the diagnostic accuracy was lower (49\%). This might be due to a different state of the patients. A pathological late enhancement occurs in patients with more severe myocarditis which may involve cellular necrosis. Therefore, not all patients with myocarditis present with a positive late enhancement pattern. Gutberlet et al. [52] also compared T1- and T2-weighted images for the diagnosis of myocarditis. The diagnostic accuracy was 72 and $68 \%$. Thus, there is an acceptable concordance between novel magnetic resonance modalities and biopsy results but still further research work has to be performed.

Comparison of echocardiography and cardiovascular magnetic resonance

There are several case reports with normal echocardiographic findings but a diagnosis of myocarditis was confirmed by cardiac magnetic resonance. Marnach et al. [80] describe a case of postpartum myocarditis in a woman with lupus anticoagulant and antiphospholipid syndrome. The diagnosis of myocarditis was confirmed by cardiac magnetic resonance but was not apparent on echocardiography. The myocarditis resolved with steroid therapy. Kontogianni et al. [81] report two male adolescents (15 and 19 years old) who were admitted due to chest pain influenced by the respiratory movements, composing a clinical setting highly indicative of acute myocarditis. The echocardiogram performed in both patients failed to reveal any regional or global wall motion abnormalities or even diastolic dysfunction and remained absolutely normal throughout their 3-month follow-up period. CMRI within 7 days using T2-weighted and gadolinium-enhanced T1weighted images demonstrated extensive focal contrast enhancement, consistent with acute inflammatory myocardial involvement. The authors conclude that contrast CMRI is a more sensitive method than the echocardiogram for the diagnosis of acute focal myocarditis.

\section{Computer tomography with multislice techniques}

Computer tomography (CT) with multislice techniques is useful in the diagnosis of coronary artery disease [82]. Brooks and Sane [83] report two patients with clinical myocarditis who had distinctive findings at coronary CT. Both patients demonstrated delayed myocardial enhancement with iodinated contrast. The morphologic features of the enhancement were similar to the myocardial enhancement with gadolinium contrast on magnetic resonance imaging recently described in patients with myocarditis, and different from the enhancement patterns seen in patients with myocardial infarction. Dambrin et al. [84] investigated the diagnostic value of ECG-gated multidetector CT in the early phase of suspected acute myocarditis in 12 consecutive patients admitted for suspected acute 
Table 1 Cardiovascular magnetic resonance in comparison to biopsy-confirmed cases

\begin{tabular}{|c|c|c|c|c|c|c|}
\hline Literature & $\begin{array}{l}\text { Number } \\
\text { of pts }\end{array}$ & $\begin{array}{l}\text { Myocardial } \\
\text { oedema present }\end{array}$ & $\begin{array}{l}\text { Late } \\
\text { enhancement } \\
\text { present }\end{array}$ & $\begin{array}{l}\text { Biopsy- } \\
\text { proven active } \\
\text { myocarditis }\end{array}$ & $\begin{array}{l}\text { Accuracy } \\
\text { in regions of late } \\
\text { enhancement }\end{array}$ & $\begin{array}{l}\text { Accuracy in regions } \\
\text { without late } \\
\text { enhancement }\end{array}$ \\
\hline Gagliardi et al. [55] & 11 & $6^{\mathrm{a}}$ & n.p. & 6 & n.p. & n.p. \\
\hline Friedrich et al. [47] & 19 & $16(84 \%)$ & n.p. & $4 / 7(57 \%)$ & n.p. & n.p. \\
\hline Roditi et al. [50] & 20 & $12^{\mathrm{b}}$ & n.p. & 4 & $100 \%$ & n.r. \\
\hline Mahrholdt et al. [63] & 32 & n.r. & $28(88 \%)$ & $20(62.5 \%)$ & $19 / 21(90 \%)$ & $1 / 11(9 \%)$ \\
\hline De Cobelli et al. [73] & 23 & $5(22 \%)^{\mathrm{c}}$ & $16(70 \%)$ & $14(61 \%)$ & $12 / 14(86 \%)$ & n.r. \\
\hline Mahrholdt et al. [6] & 128 & n.r. & $83(95 \%)$ & 87 & n.r. & n.r. \\
\hline Gutberlet et al. [52] & 83 & $72 \%^{\mathrm{d}}$ and $68 \%^{\mathrm{e}}$ & n.r. & $49 / 83(59 \%)$ & $49 \%^{\mathrm{f}}$ & $49 \%^{\mathrm{f}}$ \\
\hline
\end{tabular}

n.r. Not reported, n.p. not performed

a $\mathrm{T} 2$ spin echo

b $\mathrm{T} 1$-weighted images before and after contrast agent administration

c T2-fat saturated black blood image

d T1-weighted imaging before and after contrast agent administration

e T2-weighted triple inversion recovery imaging to calculate the oedema ratio

${ }^{\mathrm{f}}$ Difference not reported

myocarditis less than 10 days after onset of symptoms. All patients had clinical, electrocardiographic signs, and laboratory findings consistent with the diagnosis. They compared the CT results to CMRI using T1-weighted delayed enhancement images after injection of gadolinium. Extent and location of hyperenhancement at CT correlated well with that observed at MR examination. Boussel et al. [85] evaluated the accuracy of delayedenhanced multidetector computed tomography for differentiating between myocarditis and myocardial infarction in 12 patients with normal X-ray coronary angiography. Final diagnosis between myocarditis and myocardial infarction was identical for delayed-enhanced multidetector computed tomography and magnetic resonance tomography with a significant agreement for number of involved segments and transmural extension. A major limitation of cardiac computed tomography is due to radiation exposure to the patient. The use of lower tube voltages, prospective ECG pulsing and new patients protocols have recently led to dose reduction [86] but still the applied doses remain relatively high [87].

\section{Conclusion}

An autopsy series of consecutive cases have demonstrated an incidence of myocarditis at approximately 1-10\% [88]; on the contrary, myocarditis is seriously underdiagnosed clinically. In a traditional view, the gold standard has been myocardial biopsy. However, it is generally specific but insensitive for clinical use, mostly because of the focal nature of the disease. The endomyocardial procedure via the femoral vein approach under fluoroscopic guidance has a very low complication rate of $0.0-0.12 \%$ of major and $0.2-5.5 \%$ of minor complications when performed by very experienced operators and in a high volume centre [89]. In clinical practice, the overall rate of complications has been reported to range between 1 and 6\% [79, 90-92]. The mortality rate has been reported from 0.0 to $0.4 \%[3,79$, 89-91]. Thus, non-invasive approaches to detect myocarditis are necessary. The traditional diagnostic tools are ECG, laboratory values, especially troponin $\mathrm{T}$ or I, creatine kinase and echocardiography. For a long period, nuclear technique with indium-111 antimyosin antibody has been used as a diagnostic approach. In the last years, the use of this technique has declined due to radiation exposure and 48-h delay in obtaining imaging after injection to prevent blood pool effect.

Thus, a non-invasive diagnostic approach without radiation and online image availability has been awaited. Cardiac magnetic resonance has these promising characteristics. With this technique, it is possible to analyse inflammation, oedema and necrosis in addition to functional parameters such as left ventricular function, regional wall motion and dimensions. But still larger studies are warranted to further establish the different CMR modalities in the diagnosis of myocarditis.

Acknowledgments We thank Thea Hunisch for the reading of the draft of the paper and Petra Nuß for typing parts of the manuscript. There is no financial support to this study. There are no grants.

\section{Conflict of interest statement None.}

Open Access This article is distributed under the terms of the Creative Commons Attribution Noncommercial License which permits any noncommercial use, distribution, and reproduction in any medium, provided the original author(s) and source are credited. 


\section{References}

1. Feldman AM, McNamara D (2000) Myocarditis. N Engl J Med 343:1388-1398

2. Maisch B, Alter P, Karatolius K, Ruppert V, Pankuweit S (2007) The heart in cases of viral, bacterial and parasitic infections. Internist (Berl) 48:255-267

3. Mangin M, Marholdt H, Sechtem U (2006) Diagnosis of myocarditis: description and assessment of available methods. Dtsch Med Wochenschr 131:1228-1234

4. Woodruff JF (1980) Viral myocarditis. A review. Am J Pathol $101: 425-484$

5. Kühl U, Pauschinger M, Seeberg B, Lassner D, Noutsias M, Poller W, Schultheiss H-P (2005) Viral Persistence in the myocardium is associated with progressive cardiac dysfunction. Circulation 112:1965-1970

6. Mahrholdt H, Wagner A, Deluigi CC, Kispert E, Hager S, Meinhardt G, Vogelsberg H, Fritz P, Dippon J, Bock CT, Klingel K, Kandolf R, Sechtem U (2006) Presentation, patterns of myocardial damage, and clinical course of viral myocarditis. Circulation 114:1581-1590

7. Dennert R, Crijns HJ, Heymans S (2008) Acute viral myocarditis. Eur Heart J 29:2073-2082

8. Kandolf R (2004) Virus etiology of inflammatory cardiomyopathy. Dtsch Med Wochenschr 129:2187-2192

9. Yilmaz A, Mahrholdt H, Athanasiadis A, Vogelsberg H, Meinhardt G, Voehringer M, Kispert EM, Deluigi C, Baccouche H, Spodarev E, Klingel K, Kandolf R, Sechtem U (2008) Coronary vasospasm as the underlying cause for chest pain in patients with PVB19-myocarditis. Heart 94:1456-1463

10. Bowles NE, Ni J, Kerney DL, Pauschinger M, Schultheiss HP, McCarthy R, Hare J, Bricker JT, Bowles KR, Towbin JA (2003) Detection of viruses in myocardial tissues by polymerase chain reaction. Evidence of adenovirus as a common cause of myocarditis in children and adults. J Am Coll Cardiol 42:466-472

11. Maron BJ (2003) Sudden death in young athletes. N Engl J Med 349:1064-1075

12. Matsumouri A (2007) Treatment options in myocarditis: what we know from experimental data and how it translates to clinical trials. Herz 32:452-456

13. Kawai C (1999) From myocarditis to cardiomyopathy: mechanisms of inflammation and cell death: learning from the past for the future. Circulation 99:1091-1100

14. Kühl U, Pauschinger M, Bock T, Klingel K, Schwimmbeck CP, Seeberg B, Krautwurm L, Poller W, Schultheiss HP, Kandolf R (2003) Parvovirus B19 infection mimicking acute myocardial infarction. Circulation 108:945-950

15. Kindermann I, Kindermann M, Kandolf R, Klingel K, Bültmann B, Müller T, Lindinger A, Böhm M (2008) Predictors of outcomes in patients with suspected myocarditis. Circulation 118:639-648

16. Morgera T, Di Lenarda A, Dreas L, Pinamonti B, Humar F, Bussani R, Silvestri F, Chersevani D, Camerini F (1992) Electrocardiography of myocarditis revisited: clinical and prognostic significance of electrocardiographic changes. Am Heart J 124:455-467

17. Eckart RE, Love SS, Atwood JE, Arness MK, Cassimatis DC, Campbell CL, Boyd SY, Murphy JG, Swerdlow DL, Collins LC, Riddle JR, Tornberg DN, Grabenstein JD, Engler RJ (2004) Incidence and follow-up of inflammatory cardiac complications after smallpox vaccination. J Am Coll Cardiol 44:201-205

18. Lauer B, Niederau C, Kühl U, Schannwell M, Pauschinger M, Strauer BE, Schultheiss HP (1997) Cardiac troponin T in patients with clinically suspected myocarditis. J Am Coll Cardiol 30:1354-1359
19. Korff S, Katus HA, Giannitsis E (2006) Differential diagnosis of elevated troponins. Heart 92:987-993

20. Hombach V, Merkle N, Kestler HA, Torzewski J, Kochs M, Marx N, Nusser T, Burgsthaler C, Rasche V, Bernhardt P, Kunze M, Wöhrle J (2008) Characterization of patients with acute chest pain using cardiac magnetic resonance imaging. Clin Res Cardiol 97:760-767

21. Pilz G, Bernhardt P, Harrer E, Klos M, Höfling B (2008) Cardiac magnetic resonance imaging: an essential diagnostic aid in suspected myocardial re-infarction in a 40 year old woman. Clin Res Cardiol 97:280-283

22. Assomull RG, Lyne JC, Keenan N, Gulati A, Bunce NH, Davies SW, Pennell DJ, Prasad SK (2007) The role of cardiovascular magnetic resonance in patients presenting with chest pain, raised troponin and unobstructed coronary arteries. Eur Heart $\mathbf{J}$ 28:1242-1249

23. Carniel E, Sinagra G, Bussani R, Di Lenarda A, Pinamonti B, Lardieri G, Silvestri F (2004) Fatal myocarditis: morphologic and clinical features. Ital Heart J 5:702-706

24. Pinamonti B, Alberti E, Cigalotto A, Dreas L, Salvi A, Silvestri F, Camerini F (1988) Echocardiographic findings in myocarditis. Am J Cardiol 62:285-291

25. Mendes LA, Dec GW, Picard MH, Palacios IF, Newell J, Davidoff R (1994) Right ventricular dysfunction: an independent predictor of adverse outcome in patients with myocarditis. Am Heart J 128:301-307

26. Morimoto S, Kato S, Hiramitsu S, Uemura A, Ohtsuki M, Kato Y, Sugiura A, Miyagishima K, Iwase M, Ito T, Hishida $H$ (2003) Narrowing of the left ventricular cavity associated with transient ventricular wall thickening reduces stroke volume in patients with acute myocarditis. Circ J 67:490-494

27. Felker GM, Boehmer JP, Hruban RH, Hutchins GM, Kasper EK, Baughman KL, Hare JM (2000) Echocardiographic findings in fulminant and acute myocarditis. J Am Coll Cardiol 36:227-232

28. McCarthy RE III, Boehmer JP, Hruban RH, Hutchins GM, Kasper EK, Hare JM, Baughman KL (2000) Long-term outcomes of fulminant myocarditis as compared with acute (nonfulminant) myocarditis. N Engl J Med 342:690-695

29. Di Bella G, Coglitore S, Zimbalatti C, Minutoli F, Zito C, Patane' S, Carerj S (2008) Strain Doppler echocardiography can identify longitudinal myocardial dysfunction derived from edema in acute myocarditis. Int J Cardiol 12:279-280

30. Smedema JP (2007) Images in cardiovascular medicine: myocardial inflammation in viral peri-myocarditis detected by tissue Doppler echocardiography and magnetic resonance imaging. Cardiovasc J Afr 18:238-240

31. Thuny F, Avierinos J-F, Jop B, Tafanelli L, Renard S, Riberi A, Métras D, Habib G (2006) Massive biventricular thrombosis as a consequence of myocarditis. Findings from 2-dimensional and real-time 3-dimensional echocardiography Circulation 113:e932e933

32. O'Connell JB, Henkin RE, Robinson JA, Subramanian R, Scanlon PJ, Gunnar RM (1984) Gallium-67 imaging in patients with dilated cardiomyopathy and biopsy-proven myocarditis. Circulation 70:58-62

33. Shulkin BL, Wahl RL (1987) SPECT imaging of myocarditis. Clin Nucl Med 12:841-842

34. Matsuura $H$, Ishikita $T$, Yamamoto $S$, Umezawa $T$, Ito $R$, Hashiguchi R, Saji T, Matsuo N, Takano M (1987) Gallium-67 myocardial imaging for the detection of myocarditis in the acute phase of Kawasaki disease (mucocutaneous lymph node syndrome): the usefulness of single photon emission computed tomography. Br Heart J 58:385-392

35. Boccara F, Blanchard-Lemoine B, Sarda L, Bardet J, Le Guludec D, Cohen A (1998) Diagnostic strategy in acute myocarditis. Arch Mal Coeur Vaiss 91:1151-1158 
36. Khaw BA, Beller GA, Haber E, Smith TW (1976) Localization of cardiac myosin-specific antibody in myocardial infarction. J Clin Invest 58:439-446

37. Yasuda T, Palacios IF, Dec GW, Fallon JT, Gold HK, Leinbach RC, Strauss HW, Khaw BA, Haber E (1987) Indium 111monoclonal antimyosin antibody imaging in the diagnosis of acute myocarditis. Circulation 76:306-311

38. Kühl U, Lauer B, Souvatzoglu M, Vosberg H, Schultheiss HP (1998) Antimyosin scintigraphy and immunohistologic analysis of endomyocardial biopsy in patients with clinically suspected myocarditis-evidence of myocardial cell damage and inflammation in the absence of histologic signs of myocarditis. J Am Coll Cardiol 32:1371-1376

39. Carrió I, Berná L, Ballester M, Estorch M, Obrador D, Cladellas M, Abadal L, Ginjaume M (1988) Indium-111 antimyosin scintigraphy to assess myocardial damage in patients with suspected myocarditis and cardiac rejection. J Nucl Med 29:1893-1900

40. Bergler-Klein J, Sochor H, Stanek G, Globits S, Ullrich R, Glogar D (1993) Indium 111-monoclonal antimyosin antibody and magnetic resonance imaging in the diagnosis of acute Lyme myopericarditis. Arch Intern Med 153:2696-2700

41. Vilain D, Collet JP, Sarda L, Choussat R, Montalescot G, Le Guludec D, Faraggi M (1999) Acute myocarditis presenting as acute myocardial infarction and sudden death with complete atrioventricular block: value of antimyosin scintigraphy. J Nucl Cardiol 6:547-548

42. Martin ME, Moya-Mur JL, Casanova M, Crespo-Diez A, AsinCardiel E, Castro-Beiras JM, Diez-Jimenez L, Ballester M, Carrio I, Narula J (2004) Role of noninvasive antimyosin imaging in infants and children with clinically suspected myocarditis. J Nucl Med 45:429-437

43. Alexander C, Oberhausen E (1995) Myocardial scintigraphy. Semin Nucl Med 25:195-201

44. Sun Y, Ma P, Bax JJ, Blom N, Yu Y, Wang Y, Han X, Wang Y, Van Der Wall EE (2003) 99mTc-MIBI myocardial perfusion imaging in myocarditis. Nucl Med Commun 24:779-783

45. Andersson LG, Henriksen E, Damm S, Jonason T, Niklasson U, Wesslén L, Nyström-Rosander C, Maripuu E, Ringqvist I, Rolf C, Hedenstierna G, Friman G (2001) Thallium-201 myocardial imaging at rest in male orienteers and other endurance athletes. Ups J Med Sci 106:59-66

46. Skouri HN, Dec GW, Friedrich MG, Cooper LT (2006) Noninvasive imaging in myocarditis. J Am Coll Cardiol 48:2085-2093

47. Friedrich MG, Strohm O, Schulz-Menger J, Marciniak H, Luft FC, Dietz R (1998) Contrast media-enhanced magnetic resonance imaging visualizes myocardial changes in the course of viral myocarditis. Circulation 97:1802-1809

48. Liu PP, Jan AT (2005) Cardiovascular magnetic resonance for the diagnosis of acute myocarditis. J Am Coll Cardiol 45:1823-1835

49. Abdel-Aty H, Boyé P, Zagrosek A, Wassmuth R, Kumar A, Messroghli D, Bock P, Dietz R, Friedrich MG, Schulz-Menger J (2005) Diagnostic performance of cardiovascular magnetic resonance in patients with suspected acute myocarditis: comparison of different approaches. J Am Coll Cardiol 45:1815-1822

50. Roditi GH, Artnel GG, Cohen MC (2000) MRI changes in myocarditis-evaluation with spin echo, sine MR angiography and contrast enhanced spin echo imaging. Clin Radiol 55:752-758

51. Laissy JP, Hyafil F, Feldman LJ, Juliard JM, Schouman-Claeys E, Steg PG, Faraggi M (2005) Differentiating acute myocardial infarction from myocarditis: diagnostic value of early- and delayed-perfusion cardiac MR imaging. Radiology 237:75-82

52. Gutberlet M, Spors B, Thoma T, Bertram H, Denecke T, Felix R, Noutsias M, Schultheiss HP, Kühl U (2008) Suspected chronic myocarditis at cardiac MR: diagnostic accuracy and association with immunohistologically detected inflammation and viral persistence. Radiology 246:401-409
53. Wagner A, Schulz-Menger J, Dietz R, Friedrich MG (2003) Long-term follow-up of patients paragraph sign with acute myocarditis by magnetic paragraph sign resonance imaging. MAGMA 16:17-20

54. Kellman P, Aletras AH, Mancini C, McVeigh ER, Arai AE (2007) T2-prepared SSFP improves diagnostic confidence in edema imaging in acute myocardial infarction compared to turbo spin echo. Magn Reson Med 57:891-897

55. Gagliardi MG, Bevilacqua M, Di Renzi P, Picardo S, Passariello R, Marcelletti C (1991) Usefulness of magnetic resonance imaging for diagnosis of acute myocarditis in infants and children, an comparison with endomyocardial biopsy. Am J Cardiol 68:1089-1091

56. Gagliardi MG, Polletta B, Di Renzi P (1999) MRI for the diagnosis an flow-up of myocarditis. Circulation 99:458-459

57. Shen CT, Jeng CM, Lin YM, Chieng PU (1993) Intensification of relative myocardial $\mathrm{T} 2$-weighted magnetic resonance signals in patients with acute viral myocarditis: report of one case. Acta Paediatr Sin 34:405-411

58. Jeserich M, Olschewski M, Bley T, Merkle N, Kirchberger J, Pavlik G, Bode C, Geibel A (2009) Cardiac involvement after respiratory tract viral infection-detection by cardiac magnetic resonance. J Comput Assist Tomogr 33:15-19

59. Wagner A, Mahrholdt H, Holly TA, Elliot MD, Regenfus M, Parker M, Klocke FJ, Bonow RO, Kim RJ, Judd RM (2003) Contrast enhanced MRI and routine single photon emission computed tomography (SPECT) perfusion imaging for detection of subendocardial myocardial infarcts: an imaging study. Lancet 361:374-379

60. Mahrholdt H, Wagner A, Judd RM, Sechtem U (2002) Assessment of myocardial viability by cardiovascular magnetic resonance imaging. Eur Heart J 23:602-619

61. Thomson LE, Fieno DS, Abidov A, Slomka PJ, Hachamovitch R, Saouaf R, Friedman JD, Berman DS (2007) Added value of rest to stress study for recognition of artefacts in perfusion cardiovascular magnetic resonance. J Cardiovasc Magn Reson 9:733740

62. Babu-Narayan SV, McCarthy KP, Yen Ho S, Magee AG, Kilner PJ, Sheppard MN (2007) Images in cardiovascular medicine. Myocarditis and sudden cardiac death in the young extensive fibrosis suggested by cardiovascular magnetic resonance in vivo and confirmed post mortem. Circulation 166:e122-e125

63. Mahrholdt H, Goedecke C, Wagner A, Meinhardt G, Athanasiadis A, Vogelsberg H, Fritz P, Klingel K, Kandolf R, Sechtem U (2004) Cardiovascular magnetic resonance assessment of human myocarditis: a comparison to histology and molecular pathology. Circulation 109:1250-1258

64. Choudhury L, Mahrholdt H, Wagner A, Choi KM, Elliott MD, Klocke FJ, Bonow RO, Judd RM, Kim RJ (2002) Myocardial scarring in asymptomatic or mildly symptomatic patients with hypertrophic cardiomyopathy. J Am Coll Cardiol 40:2156-2164

65. Koeth O, Mark B, Kilkowski A, Layer G, Cornelius B, Kouraki K, Bauer T, Zahn R, Senges J, Zeymer U (2008) Clinical angiographic and cardiovascular magnetic resonance findings in consecutive patients with takotsubo cardiomyopathy. Clin Res Cardiol 97:623-627

66. Borchert B, Lawrenz T, Bartelsmeier M, Röthemeyer S, Kuhn H, Stellbrink C (2007) Utility of endomyocardial biopsy guided by delayed enhancement areas on magnetic resonance imaging in the diagnosis of cardiac sarcoidosis. Clin Res Cardiol 96:759-762

67. Engberding R, Yelbz TM, Breithardt G (2007) Isolated noncompaction of the left ventricular myocardium: a review of the literature two decades after the initial case description. Clin Res Cardiol 96:481-488

68. Eitel I, Fuernau G, Walther C, Razek V, Kivelitz D, Schuler G, Thiele H (2008) Delayed enhancement magnetic resonance 
imaging in isolated noncompaction of ventricular myocardium. Clin Res Cardiol 97:277-279

69. Schwab J, Haack G, Sinss D, Bär I, Zahn R (2007) Diagnosis of left ventricular myxoma with cardiac magnetic resonance imaging. Clin Res Cardiol 96:189-190

70. Dill T, Ekinci O, Hansel J, Kluge A, Breidenbach C, Hamm CW (2005) Delayed contrast-enhanced magnetic resonance imaging for the detection of autoimmune myocarditis and long-term follow-up. J Cardiovasc Magn Reson 7:521-523

71. Dziadzio M, Giovagnoni A, Pomponio G, Recanatini A, della Costanza OP, Manzin A, Casagrande W, Gabrielli A (2003) Acute myocarditis associated with adenoviral infection in a patient with scleroderma. Clin Rheumatol 22:487-490

72. Codreanu A, Djaballah W, Angioi M, Ethevenot G, Moulin F, Felblinger J, Sadoul N, Karcher G, Aliot E, Marie PY (2007) Detection of myocarditis by contrast-enhanced MRI in patients presenting with acute coronary syndrome but no coronary stenosis. J Magn Reson Imaging 25:957-964

73. De Cobelli F, Pieroni M, Esposito A, Chimenti C, Belloni E, Mellone R, Canu T, Perseghin G, Gaudio C, Maseri A, Frustaci A, Del Maschio A (2006) Delayed gadolinium-enhanced cardiac magnetic resonance in patients with chronic myocarditis presenting with heart failure or recurrent arrhythmias. J Am Coll Cardiol 47:1649-1654

74. Yelgec NS, Dymarkowski S, Ganame J, Bogaert J (2007) Value of MRI in patients with a clinical suspicion of acute myocarditis. Eur Radiol 17:2211-2217

75. Fenster BE, Chan FP, Valentine HA, Yang E, McConnell MV, Berry GJ, Yang PC (2006) Cardiac magnetic resonance imaging of myocarditis: effective use in medical decision making. Circulation 113:e842-e843

76. Varghese A, Davies S, Pennell DJ (2005) Diagnosis of myocarditis by cardiovascular magnetic resonance (Images in cardiology). Heart 91:567

77. Chow LH, Radio SJ, Sears TD, McManus BM (1989) Insensitivity of right ventricular endomyocardial biopsy in the diagnosis of myocarditis. J Am Coll Cardiol 14:915-920

78. Hauck AJ, Kearney DL, Edwards WD (1989) Evaluation of postmortem endomyocardial biopsy specimens from 38 patients with lymphocytic myocarditis: implications for role of sampling error. Mayo Clin Proc 64:1234-1245

79. Friedrich MG, Sechtem U, Holmvang G, Alakija P, Cooper LT, White JA, Abdel-Aty H, Gutberlet M, Prasad S, Aletras A, Laissy JP, Paterson I, Filipchuk NG, Kumar A, Pauschinger M, Liu P (2009) International Consensus Group on Cardiovascular Magnetic Resonance in Myocarditis: a JACC White Paper. J Am Coll Cardiol 53:1475-1487
80. Marnach M, VanWinter J, Watson W (2007) Myocarditis: an unusual cause of postpartum fever in pregnancy complicated by antiphospholipid syndrome. Am J Perinatol 24:405-408

81. Kontogianni DD, Kouris NT, Papoulia EP, Goranitou GS, Grassos HA, Babalis DK (2007) Discordance between echocardiographic and MRI findings in two cases of acute myocarditis mimicking myocardial infarction. Int J Cardiol 114:e21-e23

82. Achenbach S, Daniel WG (2007) Current role of cardiac computed tomography. Herz 32:97-107

83. Brooks MA, Sane DC (2007) CT findings in acute myocarditis: 2 cases. J Thorac Imaging 22:277-279

84. Dambrin G, Wartski M, Toussaint M, Ghostine S, Caussin C, Angel C, Lancelin B, Paul JF (2004) Anomalies in myocardial contrast uptake revealed by multislice cardiac CT during acute myocarditis. Arch Mal Coeur Vaiss 97:1031-1034

85. Boussel L, Gamondes D, Staat P, Elicker BM, Revel D, Douek P (2008) Acute chest pain with normal coronary angiogram: role of contrast-enhanced multidetector computed tomography in the differential diagnosis between myocarditis and myocardial infarction. J Comput Assist Tomogr 32:228-232

86. Pflederer T, Rudofsky L, Ropers D, Bachmann S, Marwan M, Daniel WG, Achenbach S (2009) Image quality in a low radiation exposure protocol for retrospectively ECG-gated coronary CT angiography. AJR Am J Roentgenol 192:1045-1050

87. Mayo JR, Leipsic JA (2009) Radiation dose in cardiac CT. AJR Am J Roentgenol 192:646-653

88. Gravanis MB, Sternby NH (1991) Incidence of myocarditis. A 10-year autopsy study from Malmö, Sweden. Arch Pathol Lab Med 15:390-392

89. Holzmann M, Nicko A, Kühl U, Noutsias M, Poller W, Hoffmann W, Morguet A, Witzenbichler B, Tschöpe C, Schultheiss HP, Pauschinger M (2008) Complication rat of right ventricular endomyocardial biopsy via the femoral approach: a retrospective and prospective study analyzing 3048 diagnostic procedures over an 11-year period. Circulation 118:1722-1728

90. Deckers JW, Hare JM, Baughman KL (1992) Complications of transvenous right ventricular endomyocardial biopsy in adult patients with cardiomyopathy: a seven-year survey of 546 consecutive diagnostic procedures in a tertiary referral center. J Am Coll Cardiol 19:43-47

91. Pophal SG, Sigfusson G, Booth KL, Bacanu SA, Webber SA, Ettedqui JA, Neches WH, Park SC (1999) Complications of endomyocardial biopsy in children. J Am Coll Cardiol 34:2105-2110

92. Felker GM, Hu W, Hare JM, Hruban RH, Baughman KL, Kasper EK (1999) The spectrum of dilated cardiomyopathy. The Johns Hopkins experience with 1278 patients. Medicine (Baltimore) 78:270-283 